\title{
Long-term outcome of preterm infants treated with nasal continuous positive airway pressure
}

\author{
Pia Wintermark • Jean-François Tolsa • \\ Guy Van Melle • Margarita Forcada-Guex • \\ Adrien C. Moessinger
}

Received: 21 April 2006 /Revised: 14 July 2006 / Accepted: 15 July 2006 / Published online: 17 October 2006

(C) Springer-Verlag 2006

\begin{abstract}
This study's aim was to assess neurodevelopmental and growth outcome until the age of 4 years of premature infants placed on early nCPAP, in the setting of the neonatal intensive care unit (NICU) and follow-up program of the Division of Neonatology of the Department of Pediatrics of the University Hospital, Lausanne, Switzerland. All consecutive inborn infants weighing $<1500 \mathrm{~g}$ or $<32$ weeks of gestational age admitted to the NICU during two periods of 12 months-7.1996-6.1997 and 7.19986.1999-were compared before and after the systematic application of early nCPAP. Of 172 infants admitted to the NICU, $150(87 \%)$ survived. $126(84 \%)$ were tested at 6 months' corrected age, 121 (81\%) at 18 months' corrected age, and $117(78 \%)$ at the age of 4 years. Detailed perinatal data were collected. Follow-up included neurological examination, developmental testing and measurement of growth parameters. Statistical analyses were performed. Early application of nCPAP and avoidance of mechanical ventilation showed no adverse effects on neurodevelopment and growth. A significantly higher developmental quotient was found in the nCPAP group at 18 months' corrected age. Several trends were also noted in the nCPAP group with a decrease of intraventricular hemorrhage and in "abnormal neurodevelopment" at 6 months corrected age, a bigger
\end{abstract}

P. Wintermark $(\bowtie) \cdot$ J.-F. Tolsa $\cdot$ M. Forcada-Guex $\cdot$

A. C. Moessinger

Developmental Unit, Division of Neonatology,

Department of Pediatrics,

University Hospital (CHUV) and Lausanne Medical School,

1011 Lausanne, Switzerland

e-mail: Pia.Wintermark@chuv.ch

G. Van Melle

Biostatistics Unit, Institute of Social and Preventive Medicine, University Hospital (CHUV) and Lausanne Medical School,

1011 Lausanne, Switzerland head circumference at all different tested ages and a greater height at 6 and 18 months corrected ages. In conclusion, our study of developmental outcome documents the absence of any harmful effect of early application of nCPAP to treat respiratory failure in very low birthweight infants.

Keywords Continuous positive airway pressure .

Neurodevelopment · Growth · Newborn .

Very low birthweight infants

\begin{tabular}{ll}
\multicolumn{2}{l}{ Abbreviations } \\
nCPAP & nasal continuous positive airway pressure \\
VLBW & very low birth weight \\
DQ & developmental quotient \\
GII & general intellectual index \\
NBRS & neurobiological risk score \\
IVH & intraventricular hemorrhage \\
PVL & periventricular leukomalacia \\
ROP & retinopathy of prematurity \\
AER & auditory evoked responses \\
DQ & developmental quotient \\
GII & general intellectual index
\end{tabular}

\section{Introduction}

Early nasal continuous positive airway pressure (nCPAP) use for premature infants with respiratory distress of various origins has recently been widely introduced in neonatal intensive care. It has been shown to lower the intubation rate and shorten $\mathrm{O}_{2}$ therapy without altering neonatal mortality and morbidity $[1,7,14,21,28]$. A decreased incidence of bronchopulmonary dysplasia has 
been described by several authors [2, 25], but not by others [14]. Another area of available information concerns the short-term neurodevelopmental outcomes, such as the incidence of severe (grade 3-4) intraventricular hemorrhage, periventricular leukomalacia or severe (stage 3-4) retinopathy of prematurity, which appeared unchanged by most authors [7, 11, 12]. There is also information about short-term parameters of growth, such as increased mean weight, a trend towards increased mean length and head circumference at 36 weeks corrected gestational age $[5,28]$ and shortened time to reach full oral feeds [7].

Several authors $[1,8,28,31,35]$ stressed the lack of information regarding consistent neurodevelopmental and growth outcome of neonates placed preferentially on nCPAP. Indeed, until very recently, no follow-up studies were available on the long-term neurodevelopment and growth of premature infants with early application of nCPAP. One recent descriptive study [19] found similar outcome as those described in the literature concerning preterm babies treated with mechanical ventilation, but did not directly compare these two populations.

Our study aimed at assessing the effects of early application of nCPAP on outcome until the age of 4 years (preschool age), with a detailed collection of neonatal, ventilatory, neurodevelopmental and growth data. Our target population was defined as infants with a birthweight $<1500 \mathrm{~g}$ (very low birthweight infants, VLBW) or with a gestational age $<32$ weeks, who were placed preferentially and very shortly after birth on nCPAP. This group was compared to a historical control group of infants placed preferentially on other modes of respiratory support.

\section{Subjects and methods}

All consecutive inborn infants weighing $<1500 \mathrm{~g}$ or born at $<32$ weeks of gestational age, admitted to the Neonatal Intensive Care Unit (NICU) of the Division of Neonatology of the Department of Pediatrics of the University Hospital, Lausanne, Switzerland, during two separate periods of 12 months, were compared. Patients born between July 1, 1996 and June 30, 1997, before the introduction of early nCPAP, represented the control group, and were used as historical controls. Patients born between July 1, 1998 and June 30, 1999, following the systematic introduction of early nCPAP application to treat respiratory distress, represented the nCPAP group (study group).

The major difference in management between these two study periods was the introduction of preferential use of nCPAP in the study group. In the first period, a standard ventilation approach had been followed, including the initial use of either oxyhood, conventional mechanical ventilation or high-frequency oscillatory ventilation for infants with moderate or severe respiratory distress. In the second period, standard policy in the NICU promoted the routine use of nCPAP in all infants experiencing respiratory distress of various origins. Nasal CPAP was applied via nasal cannulae "Infant Flow" at a pressure of $5 \mathrm{~cm} \mathrm{H}_{2} \mathrm{O}$ within 10 to 30 minutes of birth. Infants with marked retractions on nCPAP, $\mathrm{PaO}_{2}<50 \mathrm{mmHg}$ under $\mathrm{FiO} 20.8$ 1.0 , persisting $\mathrm{PaCO}_{2}>65 \mathrm{mmHg}$, severe or frequent apnea with bradycardia on nCPAP or metabolic acidosis (base excess $<-10 \mathrm{mmol} / \mathrm{l}$ ) were considered to be unsuccessfully managed on nCPAP and treated with mechanical ventilation. Preterm infants with no respiratory distress at birth were not placed on nCPAP. No other major changes in technologies or in nutrition protocols were introduced in the neonatal intensive care unit during the two periods.

The control group represented 102 children and the nCPAP group 87. Nine children in the control group and eight in the nCPAP group were excluded. Of these 17 excluded patients, 12 presented genetic syndromes, major congenital malformation or congenital cerebral infection, four had been immediately transferred to another hospital because of lack of space, and medical records lacked for one patient. Eleven patients died in each group, 12\% (11/93) in the control group and 14\% (11/79) in the nCPAP group, respectively. The surviving infants (i.e. $82(88 \%)$ in the control group and $68(86 \%)$ in the nCPAP group) were eligible for our prospective follow-up program, based on our birthweight or gestational age cut-offs for follow-up $(<1500 \mathrm{~g}$ and/or $<32$ weeks of gestational age). Written and oral information were given to parents about the use of the collected data concerning their children; the different testing ages were corrected ages of 6 months and 18 months, and the age of 4 years. Our follow-up program has been approved by the local ethics committee. In the control group, 65 (79\%) infants attended somatic, neurological and developmental examinations at corrected age of about 6 months, $60(73 \%)$ at the corrected age of about 18 months and $57(70 \%)$ at the age of about 4 years; respectively, 61 $(90 \%), 61(90 \%)$ and $60(88 \%)$ in the nCPAP group.

Detailed perinatal and neonatal data (obstetrical risk factors, birth data, major neonatal complications, therapies), demographic and social data were retrospectively collected until infants were discharged from the hospital. Gestational age was defined as the best obstetrical estimate (taking into account last menstrual period and/or ultrasound examination). Neurobiological risk score (NBRS) was calculated according to Brazy et al. [4]. Socio-economic status was calculated according to Largo et al. [23]. Clinical infection (antibiotic use for $>72$ hours, or change of antibiotic treatment during therapy, or positive culture), thrombocytopenia (thrombocytes $<100 \times 10^{9} / \mathrm{L}$ ), hypomagnesaemia (total magnesium $<0.7 \mathrm{mmol} / \mathrm{L}$ ), and hypothermia (axillary temperature $<36{ }^{\circ} \mathrm{C}$ ) were also noted. Criteria for the 
diagnosis of clinical chorioamnionitis included a pathological placenta or at least two of the following conditions (or only one if associated with an antibiotic treatment): maternal temperature $>38^{\circ} \mathrm{C}$ on two occasions, maternal CRP $>20 \mathrm{mg} / \mathrm{L}$, maternal leukocytosis $\left(>20 \times 10^{9} / \mathrm{L}\right.$ white blood cells), or positive bacterial culture of amniotic fluid obtained by amniocentesis. Duration of the different types of respiratory support (nCPAP, mechanical ventilation, oxyhood, and high-frequency oscillatory ventilation) was precisely collected. Intubation rate and incidence of pneumothorax were noted. Chronic lung disease was considered if infants had either supplemental $\mathrm{O}_{2}$ requirements $\geq 28$ days, or beyond 36 weeks [3, 35]. Therapies including sedation and pressor support were compared between the groups.

Short-term outcome included results of ultrasonographic examination of the brain $[10,29]$, retinopathy of prematurity (ROP) screening [6] and auditory evoked responses (AER) [30]. Infants were evaluated at follow-up with a medical history, a physical examination, a standard neurological examination and developmental testing. Development was tested routinely by using at 6 and 18 months of corrected age the Griffiths' Developmental Scales with calculation of a "developmental quotient" (DQ) [15], and mean and standard-deviations were those defined in the revised version of the Griffiths scales [20]. At the age of 4 years the McCarthy developmental scales with calculation of a "general intellectual index" (GII) [27] was used. Certified testers who performed the neurological and developmental examinations were not implicated in the analyses of this study. Major impairments included conditions that almost inevitably had a major effect on the child's life such as cerebral palsy, severe visual impairment, neurosensory hearing loss, mental retardation, epilepsy and severe psychological disorder, as defined by Fawer et al. [13]. Neuropsychological anomalies involved less severe organic conditions including neuromotor signs, minor visual impairment, minor hearing loss, language disorder and behavior disorder, as defined by Fawer et al. [13]. Patients were classified as "normal" if their developmental testing scores were less than one standard-deviation below average, as "mild retardation" if scores were between one and two standard-deviations below average, and as "severe retardation" if scores were more than two standard-deviations below average $[15,20,27]$. Patients were classified as having an "abnormal neurodevelopment" if they had at least one minor neurological abnormality or if their developmental testing scores were more than one standard-deviation below average. Weight, height and head circumference measured at the different testing ages were expressed in percentiles derived by relating the measures to the infants' corrected age, according to the Swiss national growth curves [22].
Differences in neonatal data and neurodevelopmental outcome between the groups were assessed in an univariate approach by the nonparametric Wilcoxon rank-sum (MannWhitney) test for continuous values or Fisher's exact test for categorical data.

For research questions (related to the effects of nCPAP) the $p$ value was set at 0.001 applying a Bonferroni correction for the 50 tests that were performed.

In order to control the plausible effects of the neonatal variables that were statistically different between the two groups on outcome, and to determine the exact influence of nCPAP, all comparisons at the different ages were adjusted for these variables. Baseline comparisons of the two treatment groups was set at $p<0.01$ to determine the neonatal variables for which an adjustment was warranted in later comparisons. The level of 0.01 was chosen to be sure to include all variables that might be different between the two groups and then have a plausible impact.

Furthermore, in order to control the effects of gestational age and intrauterine growth retardation, considered important determinants of outcome, we performed a complementary analysis. Using children in the two groups who were tested at the different ages, a matched pair analysis was performed using gestational age ( \pm 2 days) and small for gestational age status as matching criteria, choosing (arbitrarily) the first born match when several were available.

All calculations and tests were performed using the statistical software package Stata, Release 8.2 (Stata Corp., College Station, TX).

\section{Results}

The main neonatal characteristics of our population are described in Table 1. The two groups were comparable regarding most perinatal and neonatal data, except gestational age, clinical infection, thrombocytopenia, hypomagnesaemia, chorioamnionitis and hypothermia. Of note, there was no statistical difference in birth weight, sex distribution, socio-economic status, or total hospital stay. There was also no statistical difference in neurobiological risk score. The survival rate in infants weighing $<1500 \mathrm{~g}$ or born at $<32$ weeks gestational age was $88 \%(n=82)$ in the control group and $86 \%(n=68)$ in the nCPAP group. The mortality rates of the control group and the nCPAP group were $12 \%(11 / 93)$ and 14\% (11/79), respectively, and were not statistically different. This is in general accordance with what has been previously described in the literature [26], describing a mean mortality rate in VLBW of $8 \%$ with a range between 3 and 14\%. Among the twenty-two deceased patients (13\%), 7 died during the first day (extreme prematurity, one in the control group and six in the nCPAP 
Table 1 Neonatal data

\begin{tabular}{|c|c|c|c|}
\hline & Control group, $n=93$ & nCPAP group, $n=79$ & $p^{*}$ \\
\hline Gestational age, weeks $[$ mean $\pm \mathrm{SD}]$ & $30.1 \pm 2.7$ & $28.8 \pm 2.5$ & 0 \\
\hline \multicolumn{4}{|l|}{ Birth weight } \\
\hline grams $[$ mean $\pm \mathrm{SD}]$ & $1180.1 \pm 342.8$ & $1120.8 \pm 309.2$ & 0.3 \\
\hline patients $<1500 \mathrm{~g}[n(\%)]$ & $77(82.8)$ & $68(86.1)$ & 0.7 \\
\hline small for gestational age $\dagger[n(\%)]$ & $36(38.7)$ & $18(22.8)$ & 0.03 \\
\hline \multicolumn{3}{|l|}{$\operatorname{Sex}[n(\%)]$} & 0.4 \\
\hline male gender & $48(51.6)$ & $44(55.7)$ & \\
\hline female gender & $45(48.4)$ & $35(44.3)$ & \\
\hline Mortality rate $[n(\%)]$ & $11(11.8)$ & $11(13.9)$ & \\
\hline Neurobiological risk score (NBRS) $\ddagger[$ mean \pm SD $]$ & $10.5 \pm 6.4$ & $10.1 \pm 5.9$ & 0.8 \\
\hline Socio-economic status $\S[$ mean $\pm \mathrm{SD}]$ & $7.1 \pm 2.4$ & $7.2 \pm 2.8$ & 0.9 \\
\hline Patent ductus arteriosus $[n(\%)]$ & $37(39.8)$ & $30(38.0)$ & 0.9 \\
\hline Indomethacin $[n(\%)]$ & $18(19.4)$ & $19(24.1)$ & 0.5 \\
\hline Ligation of patent ductus arteriosus $[n(\%)]$ & $2(2.2)$ & $2(2.5)$ & 1.0 \\
\hline Clinical infection $[n(\%)]$ & $54(58.1)$ & $70(88.6)$ & $<0.0005$ \\
\hline Necrotizing enterocolitis $[n(\%)]$ & $12(12.9)$ & $7(8.9)$ & 0.5 \\
\hline Chorioamnionitis $[n(\%)]$ & $16(17.2)$ & $28(35.4)$ & 0.01 \\
\hline Thrombocytopenia $[n(\%)]$ & $48(51.6)$ & $19(24.1)$ & $<0.0005$ \\
\hline Hypomagnesaemia $[n(\%)]$ & $27(29.0)$ & $8(10.1)$ & 0 \\
\hline Hypothermia $[n(\%)]$ & $49(52.7)$ & $58(73.4)$ & 0.01 \\
\hline Total hospital stay, days $[$ mean $\pm \mathrm{SD}]$ & $53.6 \pm 34.7$ & $58.9 \pm 41.4$ & 0.1 \\
\hline \multicolumn{3}{|l|}{ Modes of respiratory support $[n(\%)]$} & $<0.0005$ \\
\hline Infants receiving no respiratory support & $7(7.5)$ & $10(12.7)$ & \\
\hline Infants receiving nCPAP only & $1(1.1)$ & $38(48.1)$ & \\
\hline Infants receiving nCPAP and other modes of respiratory support & $38(40.9)$ & $25(31.7)$ & \\
\hline Infants receiving other modes of respiratory support & $47(50.5)$ & $6(7.6)$ & \\
\hline Intubation rate $[n(\%)]$ & $64(68.8)$ & $27(34.2)$ & $<0.0005$ \\
\hline \multicolumn{4}{|l|}{ Duration of respiratory support, days $[$ mean $\pm \mathrm{SD}]$} \\
\hline Nasal continuous positive airway pressure (nCPAP) & $3.2 \pm 8.9$ & $17.7 \pm 19.9$ & $<0.0005$ \\
\hline Mechanical ventilation & $2.6 \pm 4.1$ & $1.3 \pm 3.3$ & $<0.0005$ \\
\hline Oxyhood & $3.0 \pm 8.3$ & $0.1 \pm 0.4$ & $<0.0005$ \\
\hline High-frequency oscillatory ventilation & $1.0 \pm 3.1$ & $0.3 \pm 1.2$ & 0.002 \\
\hline Oxygen supplementation & $8.9 \pm 16.2$ & $5.9 \pm 11.8$ & 0.01 \\
\hline Pneumothorax $[n(\%)]$ & $2(2.2)$ & $9(11.4)$ & 0.02 \\
\hline Chronic lung disease $[n(\%)]$, defined in infants receiving: & $7(7.5)$ & $4(5.1)$ & 1.0 \\
\hline O2 supplementation beyond 28 days & $7(7.5)$ & $4(5.1)$ & \\
\hline O2 supplementation beyond corrected age of 36 weeks & $2(2.2)$ & $0(0.0)$ & \\
\hline Morphine $[n(\%)]$ & $65(69.9)$ & $27(34.2)$ & $<0.0005$ \\
\hline Catecholamines $[n(\%)]$ & $49(52.6)$ & $19(24.1)$ & $<0.0005$ \\
\hline
\end{tabular}

* For baseline comparisons, $p<0.01$ was used to determine the variables that were different between the two groups, and for which adjustment will be performed

$\uparrow$ Small for gestational age was defined by weight at birth $<10$ th percentile for gestational age

+ Neurobiological risk score (NBRS), adapted from Brazy et al. [4]

$\S$ Socio-economic status, according to Largo et al. [23]

|| Others modes of respiratory support included mechanical ventilation, oxyhood and high-frequency oscillatory ventilation

group), 12 died between the second day and the end of the first month of life (infectious or neurological complications of prematurity, ten in the control group and four in the nCPAP group), and one in the nCPAP group died at the postnatal age of 4 months (child abuse after discharge home). The rate of intubation, the duration of mechanical ventilation and the use of morphine and catecholamines are significantly reduced in the group with preferential use of nCPAP compared with the control group. Pneumothorax was more frequent in infants with early use of nCPAP, but this was not statistically significant. It is important to note that all infants except one diagnosed with pneumothorax in the nCPAP group received mechanical ventilation. The rate of chronic lung disease is not different and is rather low in both groups.

Infants who were lost to follow-up did not differ from the studied groups concerning their perinatal and neonatal assessment, and their neurobiological risk score. 
Table 2 includes the short-term outcome measurements (intraventricular hemorrhage, periventricular leukomalacia, retinopathy of prematurity, and auditory evoked responses) and compares the findings of both groups including either the entire group or the findings restricted to survivors included in the long-term follow-up. There was no statistical difference between the two groups on the incidence of intraventricular hemorrhage and periventricular leukomalacia. Numbers of retinopathy of prematurity stages 3 or above and abnormal auditory evoked response were similar between the two groups.

Tables 3, 4 and 5 present the results of the neurodevelopmental examination at 6 months, 18 months, and at 4 years of age, respectively. The only significant difference was a higher mean developmental quotient restricted to the 18 month examination in the patient group with preferential use of nCPAP $(p=0.0002)$. The two modes of ventilatory approach had no statistical influence on the other neurodevelopmental data.

Figure 1 presents the evolution of growth parameters at the different ages. The only significant difference was a taller height equally restricted to the 18-month examination in the nCPAP group $(p=0.001)$. The other comparisons did not show any statistical difference.

Perinatal variables that were statistically different between the two groups were gestational age, clinical infection, thrombocytopenia, hypomagnesaemia, chorioamnionitis and hypothermia, as detailed in Table 1. Because

Table 2 Short-term outcome

\begin{tabular}{|c|c|c|c|c|c|c|c|}
\hline & $\begin{array}{l}\text { Control } \\
\text { group } \\
\text { all patients, } \\
n=93\end{array}$ & $\begin{array}{l}\text { nCPAP } \\
\text { group } \\
\text { all patients, } \\
n=79\end{array}$ & $p^{*}($ adjusted $p)$ & $\begin{array}{l}\text { Control } \\
\text { group } \\
\text { survivors }\end{array}$ & $\begin{array}{l}\text { nCPAP } \\
\text { group } \\
\text { survivors }\end{array}$ & $p^{*}($ adjusted $p)$ & $\begin{array}{l}\text { Matched } \\
\text { pair } \\
\text { analysis } \\
p^{*}\end{array}$ \\
\hline \multicolumn{8}{|l|}{ Intraventricular hemorrhage (IVH) } \\
\hline Number of examined infants & $n=88$ & $n=78$ & & $n=78$ & $n=68$ & & \\
\hline Grades $\dagger[n(\%)]$ & & & $0.4(0.03)$ & & & $0.2(0.09)$ & 0.1 \\
\hline Grade 0 & $64(72.7)$ & $60(76.9)$ & & $61(78.2)$ & $56(82.4)$ & & \\
\hline Grade 1 & $7(8.0)$ & $9(11.5)$ & & $6(7.7)$ & $9(13.2)$ & & \\
\hline Grade 2 & $9(10.2)$ & $3(3.9)$ & & $9(11.5)$ & $2(2.9)$ & & \\
\hline Grade 3 & $2(2.3)$ & $3(3.9)$ & & $1(1.3)$ & $1(1.5)$ & & \\
\hline Grade 4 & $6(6.8)$ & $3(3.9)$ & & $1(1.3)$ & $0(0.0)$ & & \\
\hline \multicolumn{8}{|l|}{ Periventricular leukomalacia (PVL) } \\
\hline Number of examined infants & $n=88$ & $n=78$ & & $n=78$ & $n=68$ & & \\
\hline Grades $\ddagger[n(\%)]$ & & & $0.8(0.8)$ & & & $0.8(0.7)$ & 0.7 \\
\hline Grade 0 & $76(86.4)$ & $68(87.2)$ & & $67(85.9)$ & $60(88.2)$ & & \\
\hline Grade 1 & $8(9.1)$ & $9(11.5)$ & & $7(9.0)$ & $7(10.3)$ & & \\
\hline Grade 2 & $0(0.0)$ & $0(0.0)$ & & $0(0.0)$ & $0(0.0)$ & & \\
\hline Grade 3 & $3(3.4)$ & $1(1.3)$ & & $3(3.9)$ & $1(1.5)$ & & \\
\hline Grade 4 & $1(1.1)$ & $0(0.0)$ & & $1(1.3)$ & $0(0.0)$ & & \\
\hline \multicolumn{8}{|l|}{ Retinopathy of prematurity (ROP) } \\
\hline Number of examined infants & $n=67$ & $n=61$ & & $n=67$ & $n=60$ & & \\
\hline Stages $\S[n(\%)]$ & & & 1.0 & & & 1.0 & \\
\hline Stage 3 or above & $2(3.0)$ & $1(1.6)$ & & $2(3.0)$ & $1(1.7)$ & & \\
\hline \multicolumn{8}{|l|}{ Auditory evoked responses (AER) } \\
\hline Number of examined infants & $n=43$ & $n=41$ & & $n=43$ & $n=40$ & & \\
\hline Classification $\|[n(\%)]$ & & & $0.02(0.8)$ & & & $0.02(0.9)$ & 0.03 \\
\hline $0=$ normal & $29(67.4)$ & $30(73.2)$ & & $29(67.4)$ & $30(75.0)$ & & \\
\hline $\begin{array}{l}1 \text { = first recording abnormal } \\
\text { (second recording normal) }\end{array}$ & $6(14.0)$ & $11(26.8)$ & & $6(14.0)$ & $10(25.0)$ & & \\
\hline $\begin{array}{l}2=\text { second recording abnormal } \\
\text { (first recording normal) }\end{array}$ & $3(7.0)$ & $0(0.0)$ & & $3(7.0)$ & $0(0.0)$ & & \\
\hline $3=$ first and second recordings abnormal & $5(11.6)$ & $0(0.0)$ & & $5(11.6)$ & $0(0.0)$ & & \\
\hline
\end{tabular}

* For research questions relating to the effects of nCPAP, $p$ (and adjusted $p$ ) $<0.001$ was used to determine significant effects. Adjusted $p$ represented the $p$ values of analyses performed again after adjusting for the variables that were statistically different between the two groups

$\$$ Classification of PVL, according to de Vries et al. [10]

$\S$ Classification of ROP, according to the International Committee for the Classification of the late Stages of Retinopathy of Prematurity [6]

|| Classification of AER, according to Pasman et al. [30] 
Table 3 Neurodevelopmental outcome at 6-month of corrected age

\begin{tabular}{|c|c|c|c|c|}
\hline & $\begin{array}{l}\text { Control } \\
\text { group, } \\
n=65 \dagger\end{array}$ & $\begin{array}{l}\text { nCPAP } \\
\text { group, } \\
n=61 \dagger\end{array}$ & $p^{*}($ adjusted $p)$ & $\begin{array}{l}\text { Matched pair } \\
\text { analysis, } p^{*}\end{array}$ \\
\hline Age at testing, months $[$ mean $\pm \mathrm{SD}]$ & $7.0 \pm 1.5$ & $6.6 \pm 1.3$ & 0.2 & \\
\hline \multicolumn{5}{|l|}{ Neurodevelopmental outcome } \\
\hline \multicolumn{5}{|l|}{ Developmental quotient (DQ) $\dagger$} \\
\hline Developmental quotient (DQ) $[$ mean $\pm \mathrm{SD}]$ & $98.8 \pm 14.0$ & $101.9 \pm 9.8$ & $0.1(0.6)$ & 0.4 \\
\hline Ranges & & & $0.3(0.1)$ & 1.0 \\
\hline $1=$ normal $=>85.6[n(\%)]$ & $57(87.7)$ & $58(95.1)$ & & \\
\hline $2=$ mild retardation $=74-85.6[n(\%)]$ & $6(9.2)$ & $3(4.9)$ & & \\
\hline $3=$ severe retardation $=<74[n(\%)]$ & $2(3.1)$ & $0(0.0)$ & & \\
\hline Neurological status & & & $1.0(0.8)$ & 0.2 \\
\hline $0=\operatorname{normal}[n(\%)]$ & $45(69.2)$ & $45(73.8)$ & & \\
\hline $1=1$ neuropsychological anomaly $[n(\%)]$ & $14(21.5)$ & $13(21.3)$ & & \\
\hline $2=>1$ neuropsychological anomalies $[n(\%)]$ & $3(4.6)$ & $1(1.6)$ & & \\
\hline $3=1$ major impairment $[n(\%)]$ & $1(1.5)$ & $1(1.6)$ & & \\
\hline $4=1$ major impairment $+\geq 1$ neuropsychological anomalies $[n(\%)]$ & $1(1.5)$ & $1(1.6)$ & & \\
\hline $5=>1$ major impairments $[n(\%)]$ & $0(0.0)$ & $0(0.0)$ & & \\
\hline $6=\geq 1$ major impairments $+\geq 1$ neuropsychological anomalies $[n(\%)]$ & $1(1.5)$ & $0(0.0)$ & & \\
\hline "Abnormal neurodevelopment" + & $24(36.9)$ & $16(26.2)$ & $0.2(0.09)$ & 0.09 \\
\hline
\end{tabular}

* For research questions relating to the effects of nCPAP, $p$ (and adjusted $p$ ) $<0.001$ was used to determine significant effects. Adjusted $p$ represented the $p$ values of analyses performed again after adjusting for the variables that were statistically different between the two groups

$\uparrow$ Developmental quotient was calculated using the Griffiths' developmental scales [15]

\$ An "abnormal neurodevelopment" was defined by a developmental quotient more than 1 standard-deviation below average (less than 85.6)

$[15,20]$ or a pathological neurological status

Table 4 Neurodevelopmental outcome at 18-month of corrected age

\begin{tabular}{|c|c|c|c|c|}
\hline & $\begin{array}{l}\text { Control } \\
\text { group } \\
n=60 \dagger\end{array}$ & $\begin{array}{l}\text { nCPAP } \\
\text { group } \\
n=61 \dagger\end{array}$ & $p^{*}($ adjusted $p)$ & $\begin{array}{l}\text { Matched pair } \\
\text { analysis, } p^{*}\end{array}$ \\
\hline Age at testing, months $[$ mean $\pm \mathrm{SD}]$ & $18.9 \pm 2.4$ & $18.9 \pm 1.4$ & 0.4 & \\
\hline \multicolumn{5}{|l|}{ Neurodevelopmental outcome } \\
\hline \multicolumn{5}{|l|}{ Developmental quotient (DQ) $\dagger$} \\
\hline Developmental quotient (DQ) $[$ mean \pm SD] & $104.0 \pm 11.2$ & $111.2 \pm 10.4$ & $0.0002(0.006)$ & $<0.0001$ \\
\hline Ranges & & & $0.5(0.3)$ & 1.0 \\
\hline $1=$ normal $=>94.2[n(\%)]$ & $59(98.3)$ & $59(96.7)$ & & \\
\hline $2=$ mild retardation $=82.1-94.2[n(\%)]$ & $0(0.0)$ & $2(3.3)$ & & \\
\hline $3=$ severe retardation $=<82.1[n(\%)]$ & $1(1.7)$ & $0(0.0)$ & & \\
\hline Neurological status & & & $0.6(1.0)$ & 0.3 \\
\hline $0=\operatorname{normal}[n(\%)]$ & $50(83.3)$ & $54(88.5)$ & & \\
\hline $1=1$ neuropsychological anomaly $[n(\%)]$ & $5(8.3)$ & $4(6.6)$ & & \\
\hline $2=>1$ neuropsychological anomalies $[n(\%)]$ & $2(3.3)$ & $0(0.0)$ & & \\
\hline $3=1$ major impairment $[\mathrm{n}(\%)]$ & $2(3.3)$ & $2(3.3)$ & & \\
\hline $4=1$ major impairment $+\geq 1$ neuropsychological anomalies $[n(\%)]$ & $0(0.0)$ & $1(1.6)$ & & \\
\hline $5=>1$ major impairments $[n(\%)]$ & $0(0.0)$ & $0(0.0)$ & & \\
\hline $6=\geq 1$ major impairments $+\geq 1$ neuropsychological anomalies $[n(\%)]$ & $1(1.7)$ & $0(0.0)$ & & \\
\hline "Abnormal neurodevelopment" + & $13(21.7)$ & $8(13.1)$ & $0.2(0.5)$ & 0.1 \\
\hline
\end{tabular}

* For research questions relating to the effects of nCPAP, $p$ (and adjusted $p$ ) $<0.001$ was used to determine significant effects. Adjusted $p$ represented the $p$ values of analyses performed again after adjusting for the variables that were statistically different between the two groups

$\dagger$ Developmental quotient was calculated using the Griffiths' developmental scales [15]

† An "abnormal neurodevelopment" was defined by a developmental quotient more than 1 standard-deviation below average (less than 94.2)

$[15,20]$ or a pathological neurological status 
Table 5 Neurodevelopmental outcome at age of 4 years

\begin{tabular}{|c|c|c|c|c|}
\hline & $\begin{array}{l}\text { Control } \\
\text { group, } n=57 \dagger\end{array}$ & $\begin{array}{l}\text { nCPAP } \\
\text { group, } n=60 \dagger\end{array}$ & $p^{*}($ adjusted $p)$ & $\begin{array}{l}\text { Matched pair } \\
\text { analysis, } p^{*}\end{array}$ \\
\hline Age at testing, months $[$ mean $\pm \mathrm{SD}]$ & $48.9 \pm 5.4$ & $47.2 \pm 3.3$ & 0.04 & \\
\hline \multicolumn{5}{|l|}{ Neurodevelopmental outcome } \\
\hline \multicolumn{5}{|l|}{ General intellectual index $(\mathrm{GII}) \dagger$} \\
\hline General intellectual index (GII) $[$ mean \pm SD $]$ & $101.6 \pm 17.1$ & $99.7 \pm 17.7$ & $0.2(0.6)$ & 0.8 \\
\hline Ranges & & & $0.4(1.0)$ & 1.0 \\
\hline $1=$ normal $=>84[n(\%)]$ & $46(80.7)$ & $47(78.3)$ & & \\
\hline $2=$ mild retardation $=68-84[n(\%)]$ & $8(14.0)$ & $12(20.0)$ & & \\
\hline $3=$ severe retardation $=<68[n(\%)]$ & $3(5.3)$ & $1(1.7)$ & & \\
\hline Neurological status & & & $0.08(0.7)$ & 0.6 \\
\hline $0=\operatorname{normal}[n(\%)]$ & $23(40.4)$ & $26(43.3)$ & & \\
\hline $1=1$ neuropsychological anomaly $[n(\%)]$ & $21(36.8)$ & $24(40.0)$ & & \\
\hline $2=>1$ neuropsychological anomalies $[n(\%)]$ & $8(14.0)$ & $7(11.7)$ & & \\
\hline $3=1$ major impairment $[n(\%)]$ & $0(0.0)$ & $3(5.0)$ & & \\
\hline $4=1$ major impairment $+\geq 1$ neuropsychological anomalies $[n(\%)]$ & $5(8.8)$ & $0(0.0)$ & & \\
\hline $5=>1$ major impairments $[n(\%)]$ & $0(0.0)$ & $0(0.0)$ & & \\
\hline $6=\geq 1$ major impairments $+\geq 1$ neuropsychological anomalies $[n(\%)]$ & $0(0.0)$ & $0(0.0)$ & & \\
\hline "Abnormal neurodevelopment" & $34(59.7)$ & $36(60.0)$ & $1.0(0.9)$ & 0.5 \\
\hline
\end{tabular}

* For research questions relating to the effects of nCPAP, $p$ (and adjusted $p$ ) $<0.001$ was used to determine significant effects. Adjusted $p$ represented the $p$ values of analyses performed again after adjusting for the variables that were statistically different between the two groups

$\dagger$ General Intellectual Index was calculated using the McCarthy's developmental scales [27]

¥ An "abnormal neurodevelopment" was defined by a general intellectual index more than 1 standard-deviation below average (less than 84) [27] or a pathological neurological status

these significant variables might have a plausible relationship to neurological and growth outcomes, analyses were performed again after adjusting for these variables and the results were similar. Mean developmental quotient at 18 months examination in the patient group with preferential use of nCPAP remained higher $(p=0.006)$. Height was taller at 18 months of corrected age, but the difference was not statistically significant ( $p=0.11$ ). Of note, after adjusting for the variables mentioned above, infants with preferential use of nCPAP tended to have a less severe grade of intraventricular hemorrhage $(p=0.027)$ with a risk divided by two; however, this finding did not reach statistical significance. In the same way, head circumference tended to be bigger in infants with preferential use of nCPAP at the different tested ages, but this did not reach statistical significance (respectively, $p=0.039$ at 6 months of corrected age, $p=0.030$ at 18 months of corrected age, and $p=0.12$ at the age of 4 years).

Smaller mean gestational age was observed in the nCPAP group (28.8 weeks versus 30.1 weeks for the control group, $p=0.0007$ ), and intrauterine growth retardation (weight at birth $<10$ th percentile for gestational age) tended to be more frequent in the control group (39\% versus $23 \%$ in the nCPAP group, $p=0.033$ ). Considering that these factors are important determinants of outcome we performed an additional paired comparison, as outlined in the methods section. Thirty-eight pairs of children were thus formed and the results reinforced the trends noted in the previous analyses. The value of DQ at 18 months was significantly higher in the nCPAP group $(p<0.0001)$. Height was significantly taller in the nCPAP group at 6 months $(p<0.0005)$ and at 18 months $(p<0.0001)$. A trend towards a diminution in the incidence of intracranial hemorrhage in the nCPAP group was noted ( $p=0.1$, with a risk divided by two, which may be clinically relevant). Head circumference was larger and significantly so at all three postnatal ages in the group with preferential use of nCPAP $(p<0.001$ at 6 months, $p<0.008$ at 18 months and $p<0.009$ at the age of 4 years).

\section{Discussion}

The management of respiratory distress in premature newborn infants using preferentially early nasal nCPAP rather than conventional ventilation has gained wider acceptance over the last decade. It has been shown to decrease respiratory morbidity $[2,7-9,11,14,21,28]$. Its influence on other neonatal outcome $[7,11,12]$ is debated. Controlled data on long-term neurodevelopmental outcome and somatic growth are not yet available.

The results of our study confirm the favorable influence of nCPAP on early neonatal outcome measurements, and document the safety of this approach in terms of long-term neurodevelopmental outcome and somatic growth. Indeed, follow-up data up to 4 years of age of newborn infants $<1500 \mathrm{~g}$ and/or $<32$ weeks gestation treated either with 


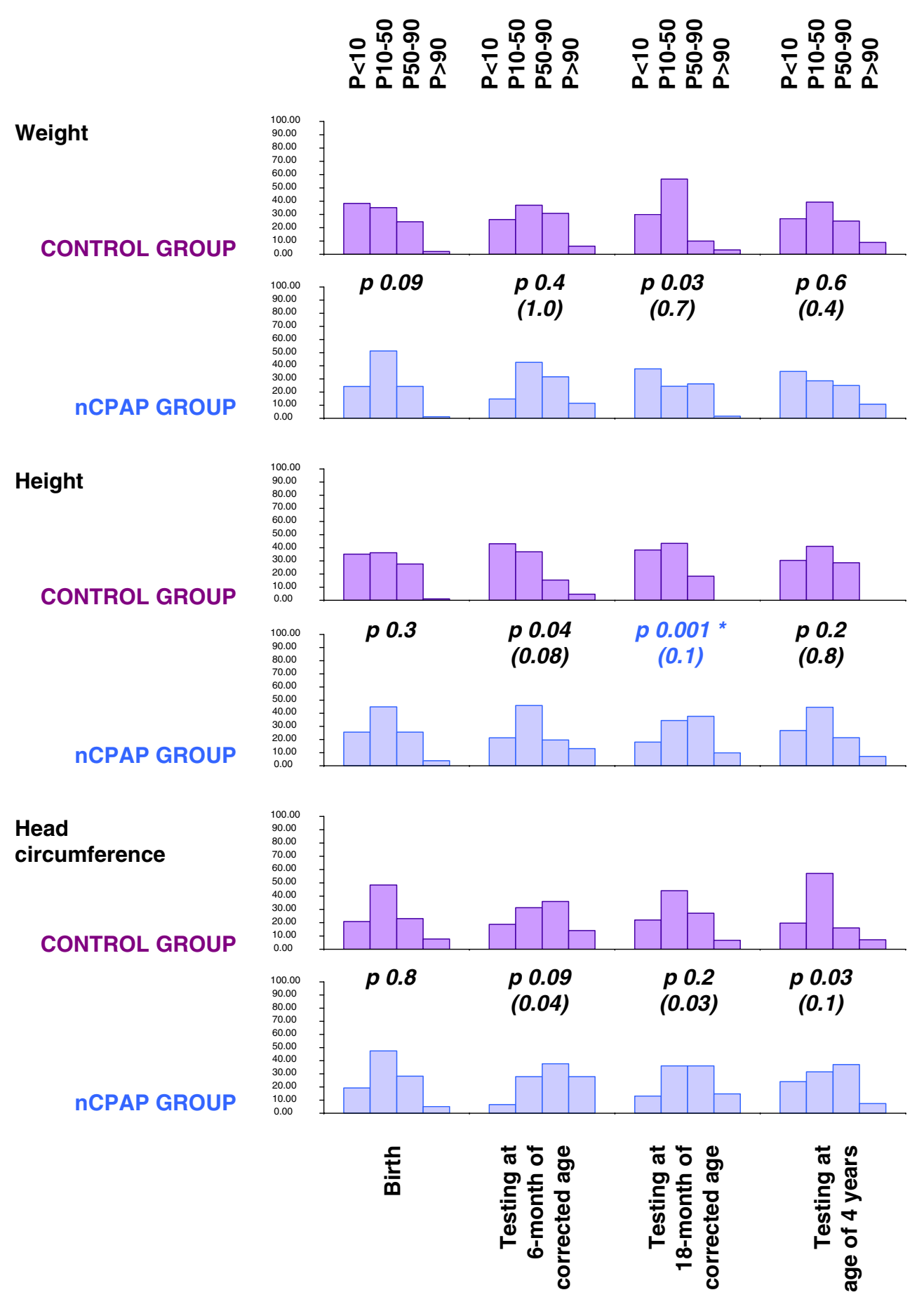

Fig. 1 Growth (weight, length and head circumference) at birth, at 6 and 18 months of corrected age, and at 4 years of age. ${ }^{*}$ For research questions related to the effects of nCPAP, $p$ (and adjusted $p$ ) $<0.001$

early nCPAP or conventional ventilation showed no significant difference. On the contrary, the nCPAP group showed several trends that seemed to suggest better outcome.

The incidence of intracranial hemorrhage documented by neonatal ultrasound was diminished in the nCPAP group was used to determine significant effects. Adjusted $p$ represented the $p$ values of analyses performed again after adjusting for the variables that were statistically different between the two groups

( $12 \%$ versus $29 \%$ in the control group, adjusted $p=0.027$ ). Although this result does not reach statistical significance, the risk is diminished by more than half (odd ratio=0.41) and this might well be clinically relevant. Of note, maximal $\mathrm{PCO}_{2}$ values were equal between the two groups (56 versus $55 \mathrm{mmHg}, p=0.059$ ), and the prevalence of clinical patent 
ductus arteriosus was not different. These combined findings could suggest a favorable influence of nCPAP on cerebral hemodynamics. This could happen via a mechanism including reduced intrathoracic pressure swings and more physiological venous return and cardiac output, the disturbances of which have been implicated as a possible mechanism for intracranial bleeding [7]. In contrast, the incidence of periventricular leukomalacia was unchanged (adjusted $p=0.84$ ). Of note, the incidence of chorioamnionitis, a known risk factor of periventricular leukomalacia, tended to be more frequent in the nCPAP group, and might then have blurred some positive effects of nCPAP on the incidence of periventricular leukomalacia. However this item was included in the variables that were statistically different between the two groups and the incidence of periventricular leukomalacia was not different between the two groups in the analyses after adjusting for these variables. Moreover, physiopathological mechanisms underlying periventricular leukomalacia seemed to be different from those of intracranial hemorrhage, and might therefore be less subject to the mode of ventilatory support.

It is important to note that all infants diagnosed with IVH 3-4, PVL 2-4 or ROP 3-4 received mechanical ventilation during the first week of life (duration between one day and more than one week).

With regards to long-term outcome, the use of nCPAP appears to diminish the risk of having an abnormal neurodevelopment at 6 months of age (22\% versus $39 \%$ in the control group, adjusted $p=0.093$ ) and to diminish as well the risk of having a DQ (developmental quotient) below one standard deviation at 6 months ( $2 \%$ versus $8 \%$ in the control group, adjusted $p=0.12$ ). This effect on the DQ seems to decrease with advancing age but is still significant at 18 months with values of 110.6 versus 104.8 after adjustment $(p=0.006)$, and disappears at the age of 4 years. Some of the neonatal effects of nCPAP on neurodevelopment might be blurred with advancing age (intervening diseases, rehospitalization rate, stimulating environment, resort to special education resources), explaining why there is no more difference at the age of 4 years.

When considering somatic growth, nCPAP use was not associated with any difference in weight whereas height tended to be taller at 6 months ( $p=0.04$, adjusted $p=0.084$ ) and at 18 months as well $(p=0.001$, adjusted $p=0.11)$. Head circumference tended to be larger at 6 months, 18 months and at the age of 4 years (respectively, $p=0.086 /$ adjusted $p=0.039$ at 6 months corrected age; $p=0.24 /$ adjusted $p=0.030$ at 18 months of corrected age; and $p=0.03$ / adjusted $p=0.12$ at age of 4 years). Considering the link between head growth and future cognitive function $[16,17$, 33], it seems important that this potential effect on head circumference be further evaluated since it could be an argument in favor of nCPAP use.
In this study, we have collected a large number of neonatal factors known to potentially influence neurodevelopment and growth. We determined for each infant its NBRS [4]; there was no statistical difference in NBRS between the 2 groups, confirming that the infants in both groups were comparably sick and equally at risk. Various perinatal variables were statistically different between the two groups (gestational age, clinical infection, thrombocytopenia, hypomagnesaemia, chorioamnionitis and hypothermia) and analyses were adjusted for these variables.

Considering all neonatal factors that were different between the two groups, and which motivated the adjustment, it is important to refer to gestational age. Gestational age was significantly lower in the nCPAP group (28.8 versus 30.1 weeks gestation in the control group, $p=0.0007$ ), and could have had a disproportionately stronger negative influence on neurodevelopment $[18,26]$. The difference in gestational age between the groups could have therefore canceled some positive effects of nCPAP in comparison to conventional ventilation. The same consideration was given to the association of fetal growth retardation (although not significantly different between the groups, $p=0.36)[24,32,34]$. For these reasons we performed additional matched pair analyses (matching individuals according to their gestational age and the presence or absence of fetal growth retardation). The results of these pair analyses have to be considered in view of the reduction in the number of pairs matched ( 38 pairs) but can be taken to confirm the results of our previous analyses.

This study describes a fairly recent population of consecutively born premature infants who have been managed in a modern neonatal ICU environment during a relatively short period of time ( 3 years). The design of the study was a retrospective "before-after trial" with a limited sample size, and presented the major limitation of not being a randomized study. It is important to note that neonatal and neurodevelopmental data were collected separately, in a coded and blinded fashion. Certified testers who performed the neurological and developmental examinations were not implicated in the analyses of this study, and were blinded to the type of respiratory support these infants received.

Another limitation is the difference in follow-up ratio between the two study periods, with less drop-outs in the group with preferential use of nCPAP. However, infants who were lost to follow-up did not differ from the studied groups concerning their perinatal and neonatal assessment and their neurobiological risk score. Of the 33 infants lost to follow-up, no information was available for 16 infants who moved away from the test center. Some neurodevelopmental information was obtained with a structured phone interview or a follow-up in another test center for 17 infants (12 in the control group and 5 in the nCPAP group). In the control group, four children were described as 
normal, four with a single neuropsychological anomaly, three with several, and one with cerebral palsy (this infant was seen at 6 and 18 months of corrected age, and the diagnosis was already reported at this time). In the nCPAP group, four were described as normal, and one with a single neuropsychological anomaly.

In summary, our study documents the safety of early nasal CPAP treatment on long-term outcome of infants $<1500 \mathrm{~g}$ or $<32$ weeks of gestational age. It thus provides an additional argument in favor of the systematic use of nCPAP as an initial approach in premature infants with respiratory distress. Prospective randomized trials and longterm follow-up studies are needed to confirm these findings.

Acknowledgments The authors thank Dr Jean-Leopold Micheli for his scientific advice and support, and the families and infants of the cohorts.

\section{References}

1. Aly H (2005) Mechanical ventilation and cerebral palsy. Pediatrics 115(6): 1765-1767

2. Avery ME, Tooley WH, Keller JB, Hurd SS, Bryan MH, Cotton RB, Epstein MF, Fitzhardinge PM, Hansen CB, Hansen TN, Hodson WA, James LS, Kitterman JA, Nielsen HC, Poirier TA, Truog WE, Wung JT (1987) Is chronic lung disease in low birth weight infants preventable? A survey of eight centers. Pediatrics 79(1):26-30

3. Bancalari E, Claure N, Sosenko IR (2003) Bronchopulmonary dysplasia: changes in pathogenesis, epidemiology and definition. Semin Neonatol 8(1):63-71

4. Brazy JE, Eckerman CO, Oehler JM, Goldstein RF, O'Rand AM (1991) Nursery neurobiologic risk score: important factor in predicting outcome in very low birth weight infants. J Pediatr 118 (5):783-792

5. Carlo WA, Stark AR, Wright LL, Tyson JE, Papile LA, Shankaran S, Donovan EF, Oh W, Bauer CR, Saha S, Poole WK, Stoll B (2002) Minimal ventilation to prevent bronchopulmonary dysplasia in extremely-low-birth-weight infants. J Pediatr 141 (3):370-374

6. Committee for the Classification of Retinopathy of Prematurity (1984) An international classification of retinopathy of prematurity. Arch Ophthalmol 102(8):1130-1134

7. De Klerk AM, De Klerk RK (2001) Nasal continuous positive airway pressure and outcomes of preterm infants. J Paediatr Child Health 37(2):161-167

8. de Klerk AM, de Klerk RK (2001) Use of continuous positive airway pressure in preterm infants: comments and experience from New Zealand. Pediatrics 108(3):761-763

9. De Paoli AG, Morley C, Davis PG (2003) Nasal CPAP for neonates: what do we know in 2003? Arch Dis Child Fetal Neonatal Ed 88(3):F168-F172

10. de Vries LS (1996) Neurological assessment of the preterm infant. Acta Paediatr 85(7):765-771

11. Dimitriou G, Greenough A, Kavvadia V, Laubscher B, Alexiou C, Pavlou V, Mantagos S (2000) Elective use of nasal continuous positive airways pressure following extubation of preterm infants. Eur J Pediatr 159(6):434-439
12. Elgellab A, Riou Y, Abbazine A, Truffert P, Matran R, Lequien P, Storme L (2001) Effects of nasal continuous positive airway pressure (NCPAP) on breathing pattern in spontaneously breathing premature newborn infants. Intensive Care Med 27 (11):1782-1787

13. Fawer CL, Besnier S, Forcada M, Buclin T, Calame A (1995) Influence of perinatal, developmental and environmental factors on cognitive abilities of preterm children without major impairments at 5 years. Early Hum Dev 43(2):151-164

14. Gittermann MK, Fusch C, Gittermann AR, Regazzoni BM, Moessinger AC (1997) Early nasal continuous positive airway pressure treatment reduces the need for intubation in very low birth weight infants. Eur J Pediatr 156(5):384-388

15. Griffiths R (1954) The abilities of babies; a study in mental measurement. University of London Press, London

16. Gross SJ, Eckerman CO (1983) Normative early head growth in very-low-birth-weight infants. J Pediatr 103(6):946-949

17. Hack M, Breslau N, Weissman B, Aram D, Klein N, Borawski E (1991) Effect of very low birth weight and subnormal head size on cognitive abilities at school age. N Engl J Med 325 (4):231-237

18. Hack M, Wilson-Costello D, Friedman H, Taylor GH, Schluchter M, Fanaroff AA (2000) Neurodevelopment and predictors of outcomes of children with birth weights of less than $1000 \mathrm{~g}$ : 1992-1995. Arch Pediatr Adolesc Med 154(7):725-731

19. Hansen BM, Hoff B, Greisen G, Mortensen EL (2004) Early nasal continuous positive airway pressure in a cohort of the smallest infants in Denmark: neurodevelopmental outcome at five years of age. Acta Paediatr 93(2):190-195

20. Hanson R, Smith JA, Hume W (1985) Achievement of infants on items of the Griffiths scales: 1980 compared with 1950. Child Care Health Dev 11(2):91-104

21. Joris N, Sudre P, Moessinger A (2000) Early application of CPAP in newborns with gestational age below 34 weeks lowers intubation rate and shortens oxygen therapy without altering mortality and morbidity. Schweiz Med Wochenschr 130 (49):1887-1893

22. Largo RH, Walli R, Duc G, Fanconi A, Prader A (1980) Evaluation of perinatal growth. Presentation of combined intraand extrauterine growth standards for weight, length and head circumference. Helv Paediatr Acta 35(5):419-436

23. Largo RH, Pfister D, Molinari L, Kundu S, Lipp A, Duc G (1989) Significance of prenatal, perinatal and postnatal factors in the development of AGA preterm infants at five to seven years. Dev Med Child Neurol 31(4):440-456

24. Latal-Hajnal B, von Siebenthal K, Kovari H, Bucher HU, Largo RH (2003) Postnatal growth in VLBW infants: significant association with neurodevelopmental outcome. J Pediatr 143 (2):163-170

25. Latini G, De Felice C, Presta G, Rosati E, Vacca P (2003) Minimal handling and bronchopulmonary dysplasia in extremely low-birth-weight infants. Eur J Pediatr 162(4):227-229

26. Lemons JA, Bauer CR, Oh W, Korones SB, Papile LA, Stoll BJ, Verter J, Temprosa M, Wright LL, Ehrenkranz RA, Fanaroff AA, Stark A, Carlo W, Tyson JE, Donovan EF, Shankaran S, Stevenson DK (2001) Very low birth weight outcomes of the national institute of child health and human development neonatal research network, January 1995 through December 1996. NICHD Neonatal Research Network. Pediatrics 107(1):E1

27. McCarthy D (1972) Manual for the McCarthy scales of children's abilities. The Psychological Corporation, New York

28. Narendran V, Donovan EF, Hoath SB, Akinbi HT, Steichen JJ, Jobe AH (2003) Early bubble CPAP and outcomes in ELBW preterm infants. J Perinatol 23(3):195-199

29. Papile LA, Burstein J, Burstein R, Koffler H (1978) Incidence and evolution of subependymal and intraventricular hemorrhage: a 
study of infants with birth weights less than 1,500 gm. J Pediatr 92(4):529-534

30. Pasman JW, Rotteveel JJ, Maassen B, de Graaf R, Kollee LA (1998) Neonatal risk factors and risk scores including auditory evoked responses. Eur J Pediatr 157(3):230-235

31. Polin RA, Sahni R (2002) Newer experience with CPAP. Semin Neonatol 7(5):379-389

32. Pryor J, Silva PA, Brooke M (1995) Growth, development and behaviour in adolescents born small-for-gestational-age. J Paediatr Child Health 31(5):403-407
33. Simon NP, Brady NR, Stafford RL (1993) Catch-up head growth and motor performance in very-low-birthweight infants. Clin Pediatr (Phila) 32(7):405-411

34. Sung IK, Vohr B, Oh W (1993) Growth and neurodevelopmental outcome of very low birth weight infants with intrauterine growth retardation: comparison with control subjects matched by birth weight and gestational age. J Pediatr 123(4):618-624

35. Walsh MC, Wilson-Costello D, Zadell A, Newman N, Fanaroff A (2003) Safety, reliability, and validity of a physiologic definition of bronchopulmonary dysplasia. J Perinatol 23(6):451-456 